\title{
Opening Pandora's box: implementing a standards-based approach to the management of course information in UK higher education
}

\author{
Dr Gill Ferrell ${ }^{1}$, Janette Hillicks ${ }^{2}$ \\ ${ }^{1}$ Jisc infoNet, Northumbria University, Hadrian House, Higham Place, Newcastle NE1 8AF, UK, \\ gill.ferrell@northumbria.ac.uk \\ 2 Jisc infoNet, Northumbria University, Hadrian House, Higham Place, Newcastle NE1 8AF, UK, \\ janette.hillicks@northumbria.ac.uk
}

\section{Keywords}

Advertising, archi, archimate, business process, course, data, data feed, enterprise architecture, information management, key information set, MLO-AD, modelling, process map, process improvement, standards, Unistats, XCRI-CAP.

\section{ABSTRACT}

Course information lies at the heart of university and college business processes and providing information about learning opportunities to existing and prospective students is a fundamental part of delivering the business of higher education. Despite the essential nature of this information, the management of course data remains a complex, and costly, process and evidence suggests that prospective students find it difficult to access reliable information about certain types of provision.

Jisc has been working for some time on the development of common data standards to facilitate the exchange and presentation of this type of information (in particular through development of a standard for course advertising known as XCRI-CAP: eXchanging Course Related Information Course Advertising Profile which influenced the European Metadata for Learning Opportunities - Advertising standard).

From September 2011 through to March 2013 Jisc funded a sector wide programme, the Course Data Programme: making the most of course information, to support improved management of course information. 93 universities and colleges participated in stage one of the programme to review their readiness for standardising their approach to course information and to develop an implementation plan and 63 of those continued into stage two of the programme to implement their proposals and deliver 'feeds' of course information for external use. This paper looks at the experiences of those institutions in trying to make the most of one of their most important data assets.

At a casual glance, the scope of the programme may seem quite limited and strictly technical in nature. The requirement on HE institutions could be stated quite simply as:' The production of a machine readable 'feed' of course information in a standardised format'. This does however mask the considerable distance many universities and colleges needed to travel in order to be able to collate and present their data in this way. The overall intention of the programme was always to expose the wider issues around the management of course information and to offer a standardsbased approach as a common way for the sector to move forward.

This paper focuses on techniques applied and lessons learned that may be of value to other EUNIS members and highlights open source products and guidance materials that are openly available for others to use.

\section{INTRODUCTION}

Course information lies at the heart of university and college business processes and providing information about learning opportunities to existing and prospective students is a fundamental part of delivering the business of higher education. Despite the essential nature of this information, the management of course data remains a complex, and costly, process and evidence suggests that prospective students find it difficult to access reliable information about certain types of provision.

Jisc has been working for some time on the development of common data standards to facilitate the exchange and presentation of this type of information (in particular through development of a 
standard for course advertising known as XCRI-CAP: eXchanging Course Related Information Course Advertising Profile which influenced the European Metadata for Learning Opportunities - Advertising standard).

From September 2011 through to March 2013 Jisc funded a sector wide programme, the Course Data Programme: making the most of course information, to support improved management of course information. 93 universities and colleges participated in stage one of the programme to review their readiness for standardising their approach to course information and to develop an implementation plan and 63 of those continued into stage two of the programme to implement their proposals and deliver 'feeds' of course information for external use. This paper looks at the experiences of those institutions in trying to make the most of one of their most important data assets.

At a casual glance, the scope of the programme may seem quite limited and strictly technical in nature. The requirement on HE institutions could be stated quite simply as:' The production of a machine readable 'feed' of course information in a standardised format'. This does however mask the considerable distance many universities and colleges needed to travel in order to be able to collate and present their data in this way. The overall intention of the programme was always to expose the wider issues around the management of course information and to offer a standardsbased approach as a common way for the sector to move forward.

\section{DEFINING THE BASELINE}

As part of the first stage of the programme, participating institutions were invited to take part in a self assessment exercise to help determine their state of readiness for implementing a standardised approach to course marketing information. The exercise was undertaken using a Self Assessment Framework (SAF) which is available for others to use via the XCRI Knowledge Base.

The SAF identifies four main areas of readiness:
A. Institutional Strategic Policy
B. Planning the Output
C. Management Implementation
D. Technical Implementation

and the response to a detailed set of questions results in the allocation of a Red/Amber/Green status with regard to each of the areas. The results were helpful to the project teams in terms of identifying areas of risk and showing where additional effort may need to be targeted. The SAF contains a limited number of questions that may only be relevant to UK universities but, for the most part, it presents a useful set of questions for any university looking at how it manages its course data.

Having undertaken the SAF, a few institutions decided not to proceed to bid to join the second stage of the programme because they realised the enormity of the task facing them and found they were not ready to undertake the work at this point. The majority of institutions fell into the 'amber' category under each of the SAF headings suggesting they had done some of the necessary ground work but that there was still a significant need for additional support. However, with over half of the institutions still needing to take some key policy decisions and a similar amount still needing to clarify exactly what data they held and where it was stored, it was evident that further issues were likely to arise during the implementation phase.

\section{PANDORA'S BOX}

An analogy that has been used a lot over the last two years to describe how these, apparently simple, projects have unearthed a range of problems with far reaching consequences is the opening of Pandora's box. In Greek mythology Pandora unleashed all the evils of the world and the Jisc course data programme unleashed all the evils of data management within complex organisations.

In most cases the HE institutions involved had greatly underestimated the diversity of information sources/systems and the complexity of the business processes that surrounded their management of course information. It dawned on many that in order to produce the standard course advertising feed they did indeed need to take a root and branch review of the whole course information life-cycle.

'The most valuable lesson we have learnt is that no one person has a comprehensive understanding of the processes used to develop our course and module specification and the production of our course marketing material. Key stakeholders understand the components of 
the process that they are responsible for but have a more limited grasp of the processes that follow.' (University of East London)

'Whilst the University achieved Jisc funding to undertake the production of the XCRI-CAP feed, it is clear the larger institutional issue regarding course management is the main purpose of the project. It has been interesting to discover that the University is not the only HEI with this problem and has been re-assured in finding how common this problem is.' (University of Bradford)

'Although our original focus for the project was on XCRI CAP as a technology, we have very quickly realised that the main difficulty with the project lies in improving the structure and organisation of course information in a way that allows it to be processed into a format like XCRI CAP.' (Burton and South Derbyshire College)

'We have come to realise that course data is a much bigger area than it first appears.' (University of Sheffield)

This is not the first time that the management of course information has revealed itself to be a significant problem in the HE sector. A four-year Jisc programme on Institutional Approaches to Curriculum Design (2008 2012) worked with 12 universities on very large-scale projects to look at how technology could support transformation of the entire curriculum life-cycle from aligning the portfolio of courses to institutional mission, through market research and course development to quality assurance and enhancement, resource allocation, timetabling, recruitment and assessment. These projects too found that the management of course information lay at the heart of the problems they were trying to solve.

A baseline review found that: '... course information was not managed as a valuable institutional asset or a shared resource for staff and students, but in an ad hoc way, often requiring multiple points of data entry. Course information was scattered, document-based, poorly used, and unreliable. Stakeholders had little incentive to engage with the mandated processes for recording course information, since they did not generally experience this information as trustworthy or supportive of day-to-day curriculum tasks.' (Beetham 2009)

Taken together these two Jisc programmes show the scale and pervasiveness of the problem facing the sector. That these findings may be taken as widely representative of the situation in UK HE as a whole is further supported by the findings of a review of the $\mathrm{HE}$ data and information landscape undertaken by the Higher Education Statistics Agency (HESA) in 2012 on behalf of the Regulatory Partnership Group. Course information is needed for many different purposes but the processes to create and manage the information are inefficient (both administratively and academically) and take place in silos (in organisational and data storage terms) with resulting implications for data quality and fitness for purpose.

Along with all the horrors Pandora's box did of course also contain Hope and the course data projects set out to tackle their data demons with their own ray of hope in the form of the XCRI-CAP standard.

XCRI-CAP version 1.1 was endorsed in January 2009 by the UK's Information Standards Board (ISB) as the UK's eProspectus standard. The ISB is part of the Department For Education and is the official authority for information and data standards in education, skills and children's services.

A European standard called 'Metadata for Learning Opportunities - Advertising' (MLO-AD) was approved early in 2011 and has been strongly influenced by XCRI-CAP. XCRI-CAP version 1.2 conforms to the requirements of the MLO-AD European Norm.

\section{WHY IS MANAGING COURSE INFORMATION DIFFICULT?}

In one sense courses are products like any other and a standards-based approach is aimed at helping users of course information compare those products or undertake reliable statistical analysis based upon them.

To take the product analogy further: in a supermarket there are a range of products from many different places, but you can pick something up and know where to look for the weight, the size, the dietary information etc. When you take a product to the cash register it doesn't matter if you are in an international supermarket chain or your local shop, the equipment will be able to read the barcode and know what it is selling you. This form of fundamental data exchange and interoperability is taken for granted in many areas of everyday life. 
It is difficult however to take the analogy much further because a learning experience cannot be readily understood in terms of size, weight and other readily comparable characteristics. This is not to say that it is not incumbent on providers of higher education to try and present information about their 'products' in ways that enable rather than inhibit learner choice. Indeed in the UK there is a strong government agenda for improved public information about higher education resulting in the introduction in 2012 of a Key Information Set (KIS) available to prospective students via the government's Unistats website. A data standard to support the management of course information does however need to be able to deal with the richness of the data and indeed XCRI-CAP (Course Advertising Profile) is only one aspect of a more comprehensive XCRI (eXchanging Course Related Information) standard.

Much of the difficulty in managing course information however relates to its origins and the business processes that surround its creation and use. Universities need to provide course information to a wide range of internal and external stakeholders who often speak very different languages. Students, academics, quality officers, planners and regulators all want slightly different, though overlapping, course information. The various stakeholders do indeed have different answers to the question 'What is a Course?' addressed in a publication developed as part of the programme (HESA 2012).

Course information is initially generated by academics and is generally first presented in ways that meet the needs of university quality approval processes i.e. structured in a particular way and presented in academic terms that may not be readily accessible to non-specialists. Because few people not concerned with the quality approval process previously had any need for that information it was often created and stored in paper-based forms. The information to describe the course in academic terms might then have to be re-written by a marketing department to send to use for the prospectus for marketing to students. It might also be rewritten a number of other times e.g. for use in student handbooks or to capture it in a form required the university's student record, finance and planning information systems.

'Perhaps the most important lesson we have learned so far is that the complexity of the university's current systems and workflows by which on-line and paper-based course data is created, edited and archived should not be underestimated.' (University of Kent)

'Something else we have realised is just how critical this project is for the institution - not only because of the efficiencies to be gained by using the XCRI-CAP system, but also because of the vulnerabilities intrinsic to our current system.' (Birkbeck, University of London).

Added to this is the complexity of versioning i.e. changes to the course over time. Some changes may relate to things like teaching or assessment patterns, which need to be accurately recorded for timetabling purposes. This kind of regular refreshing of a course may result in a situation where students entering year 1 are studying a different version of the course to those in years 2 or 3 . The overall course identifier and key information such as the title might not change but a record of the different versions is required. This record will need to be stored for a considerable period of time as alumni may come back many years in the future to ask for transcripts etc. Planning and marketing departments on the other hand want information about courses that will be offered in the future. Maintaining accurate records of an entity such as a course in its past, present and future versions is sufficiently challenging in information systems; the task becomes significantly more difficult when some of the key information sources are paper-based.

'This project has highlighted inefficient practices across several areas, with information held by individuals; different versions being circulated and confusion about which was the final version. The project has enabled us to identify current practice and transform it into one structured, organised system.' (Arts University College at Bournemouth)

'The existing process currently (and for the foreseeable short to medium term) relies heavily on multiple versions of single documents being created and passed to various committees - leaving potential room for error and silo methods of storage of this information.' (Staffordshire University) 


\section{DATA QUALITY}

It was inevitable, given the complexity and inconsistency of business processes, that many projects also unearthed considerable issues relating to the quality of course data.

Immediately it became clear that the process was both very manual and not particularly well regulated and a 'dummy' run of an XML feed suggested that even for the meeting of the predefined statutory fields we couldn't guarantee the quality of our data'. (Coventry University)

For some institutions the examination of their current practice highlighted the absence of formal policies in relation to data management: '... the lack of campus-wide agreement on how data is originated, disseminated and kept up to date and by whom means that the success of the operation is over reliant on the skills, experience and determination of a few key members of staff.' (University of Kent)

In some cases this lack of policy resulted in inconsistent information across various sources such as the prospectus, institutional website and individual school web pages.

The University of Hertfordshire has been prompted to create a data definitions list detailing how they approach each data item within the project and how this might vary for different audiences and this 'live' document has proven to be a useful starting point for resolving issues. The project team is also looking at 'New ways of recording information that was not previously kept within our authoritative systems, such as the Abstract field for XCRI-CAP, and details of all Professional Statutory and Regulatory Bodies in a format that will support XCRI-CAP, the KIS, our website and internal reporting.'

For the University of Hertfordshire 'Record once, use multiple times' has become a key part of the ethos of the project although they note the difficulty of implementing such an approach and, in particular, balancing the need for consistency (which might point to central input of data) against the benefits of distributed data input close to the point of origin.

Aston University has produced a useful model (shown below) summarising the various sources of course information available to external audiences and indicating the way in which the various sources increase in detail and timeliness whilst retaining a small core of information.

\section{UNDERSTANDING THE BUSINESS PROCESSES ISSUES}

We have identified that managing course information is a complex matter and that weaknesses in the business processes that support this have serious implications for data quality. However even getting to the stage where a large and complex organisation understands the nature of its particular problems can consume considerable time and resource due to the number of stakeholders involved and the complexity of the processes.

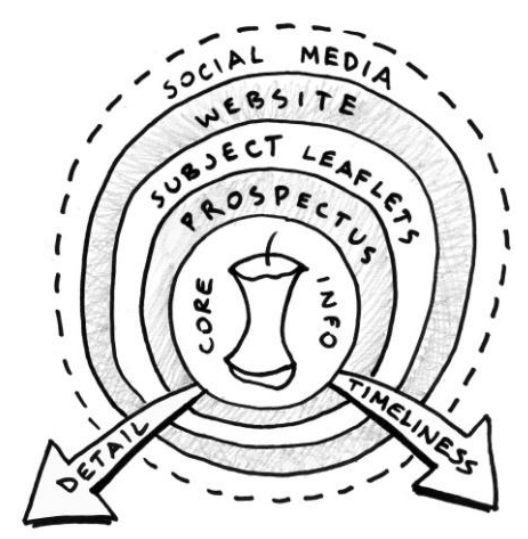

Because there is unlikely to be any single individual, or group of people, who has a detailed understanding of all of the business processes relating to the course life-cycle, it is necessary to engage a wide group of stakeholders and create an effective dialogue between them in order to gain a complete picture of the current situation and understand the implications of any changes.

The roles of stakeholders mentioned as playing an important part in this programme included: Academics, Administrators, Admissions staff, Business Support, Director of Advancement, Executive Development, Heads of School, International Development, Quality Assurance, Registry, Short Courses staff, Strategic Planning, Student and Academic Affairs Services, staff responsible for Summer Study courses and Study Abroad and Widening Participation staff.

In many cases this was the first time the groups of staff concerned had worked together on a project. This inevitably brings its own challenges but the diverse perspectives offered are necessary if the projects are to deliver solutions that really meet the objective of achieving efficiencies by creating a single source of data that can be reused for many different purposes and many of the projects have found that working with cross functional focus groups and working groups has proven an effective means of driving change. 
Brunel University has a well developed approach to stakeholder engagement and has developed a novel adaptation of the Appreciative Inquiry (Al) method. Al focuses on building on the positive aspects of existing practice but, when reviewing processes, people often find it easiest to start by identifying the negative aspects:

'With this in mind, ... we decided to open each workshop with a brief introduction focussing on the work of Edward de Bono and his Six Thinking Hats; for the purposes of our project - the negative black hat. We identified that if stakeholders 'released' their negative thoughts at the door ... via physically writing them down on post-it notes and sticking them to the black hat, they felt more represented. It also made them prepared for the workshop and in a different mind-set, thus ready to proceed forwards and embrace Al. Interesting, we strongly felt that this hybrid structure of the negative black hat metaphor combined with the traditional Al mechanism worked exceedingly well.' (Brunel University)

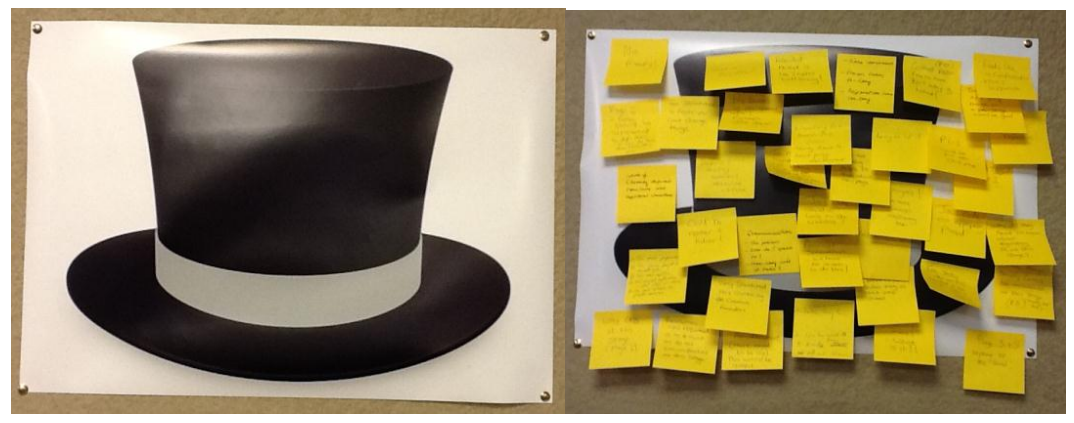

There is more about the Brunel University approach to Al on the project blog.

There is also more about approaches to stakeholder engagement in major change projects on the Jisc Design Studio.

The mapping of existing processes reveals that commonly business processes tend to grow incrementally, with each part of the organisation adopting the solution that best meets its needs at a particular time, and processes can often be built upon and adapted to cope with organisational and system change without anybody ever taking an overview of the process from end to end. The projects used a variety of techniques to map their current processes and many of the tools for process mapping are described further on the Jisc infoNet website. The results were very revealing:

'The mapping of business processes is challenging as many stages are multi-stakeholder and some practices are undocumented.' (The Arts University College at Bournemouth)

'Research has revealed workflows and work methods which were previously unclear or not formally documented.' (The Courtauld Institute of Art)

The process review activities undertaken by the projects found common problems to be:

- silo working

- duplication of data entry

- poor version control

- data definition/training issues leading to poor quality data

- lack of policy and undocumented processes

- heavy reliance on a few experts

- inability to re-purpose information

A few quotes serve to highlight the widespread issues:

'It has been verified that there are many single points of failure across all schools in the current course and module approval process both for continuing courses and new courses.' (Cranfield University)

'... we have learned the difficulty in getting changes to processes and data definitions agreed across the University. This is partly the result of there being no defined and agreed business process and business data owners, and the lack of embedded change management processes.' (London Metropolitan University)

Whilst the realisation of the extent of inefficiency and duplication in current systems may be painful, the situation is not unusual and similar stories are repeated right across the sector. Identifying the issues is however probably the most important step in enabling the institution to move forward. 


\section{IMPROVING BUSINESS PROCESSES}

Many of the tools used in mapping business processes to identify the problems can also aid in redesign although in many cases people tend to use relatively simple techniques to map existing processes to aid understanding by a wide range of stakeholders and more sophisticated modelling tools to develop their roadmap for the future. There is more on this topic in the Jisc infoKit on Process Improvement.

Many projects are trying to take a holistic view through the application of Enterprise Architecture (EA) techniques. EA is a high level, strategic technique designed to help senior managers achieve business and organisational change and there is more about EA in the Improving Organisational Efficiency suite of resources on the JISC infoNet website. '... it is essential that whatever we develop aligns to the wider course information processes and is future proofed to ensure sustainability.' (University of Central Lancashire)

EA is giving the projects a roadmap for the future even though many are having to be pragmatic about the realities of implementation and effect change in a more piecemeal fashion than they may ideally have chosen. Many of the projects to implement standardised marketing information are taking place in the context of one or more major system replacements including replacement of student records systems, content management systems, institutional websites and replacement or development of systems to manage course information.

One of the most popular approaches amongst these projects, particularly amongst those who are adopting EA techniques, is the use of the Archi modelling tool developed by Jisc. Archi is a free, open source, cross-platform tool to create Archimate models. Archi has been widely adopted for real-world use in the commercial and educational sectors and is used by major global companies and consultants. It is rapidly becoming the de facto ArchiMate modelling tool.

An example of applying EA thinking to solve specific problems without having to commit to a full enterprise approach is demonstrated by Staffordshire University and summed up in an article on 'Improving the Management of Course Information at Staffordshire'.

\section{COURSE INFORMATION SYSTEMS}

We have already highlighted the extent to which information associated with course approval, e.g. programme and module specifications, is often entirely document-based but the review activities undertaken by the projects also revealed many other risks associated with current systems used for storing critical data e.g. Birkbeck, University of London identified itself as 'extremely vulnerable' in holding its course catalogue in a product that is no longer supported by the supplier, thus making them reliant on a single individual in their own IT department, and in lacking documentation about the system and processes: 'A vulnerability in our current course publishing system is the lack of documentation relating to how we currently publish our course catalogue online (most of the information is held in the heads of critical course staff).' (Birkbeck, University of London)

Many institutions unearthed data sources of which central IT services were previously unaware: 'The majority of locally held data is stored on shared drives and individual's PCs. However it did emerge that two Schools do run their own database for their curriculum data.' (University of Birmingham).

Some institutions were applying workarounds which were becoming unsustainable 'Relying on manual intervention to compensate for a database configuration which is no longer suited to the data may have costs which are sustainable initially but increase when the uses of the database multiply.' (University of the West of England).

A similar point was made by the University of Bolton who identified significant data integrity issues stemming from the ways in which end users adapt systems to meet their own needs: 'In seeing unused tables/fields it seems perfectly reasonable to colleagues to rename and reuse for different purposes.' (University of Bolton) this included examples such as setting courses to run for 100 years to ensure they are picked up in lists of current courses and prefixing titles of courses no longer current with XXX.

The whole area of curriculum management has long appeared to be a weak point in the suite of commercial information systems available to the sector. Curriculum management is not of itself a core function of student records systems and, although many of them have optional add-ons, few institutions appear entirely satisfied with the choices on offer. 
This issue featured prominently in the Institutional Approaches to Curriculum Design programme and those projects have produced some useful resources on their approaches:

- Manchester Metropolitan University (MMU) was unable to find a commercial system that would scale to its needs and so opted for an in-house implementation (although it does not view this as a permanent solution). MMU has produced a generic set of stakeholder requirements which were used to frame its in-house implementation (case study on developing stakeholder requirements for an academic database) and a host of findings on what is still the most thorough reform of course information management in the sector.

- Cardiff University created an institution wide academic database and has released the full technical specification for their work based on the SITS student record system and use of RESTful web services.

- The University of Strathclyde developed a solution using Microsoft SharePoint and details of its work can be found in the PiP Technical Development Report.

- Birmingham City University also adopted a Microsoft SharePoint solution and has detailed its technical journey in a Sharepoint blog.

The Jisc Flexible Service Delivery programme also explored this issue through an investigation of product modularisation i.e. attempting to take the curriculum management module of a proprietary system and make it available via the Cloud to a range of institutions with different student records systems by making use of XCRI and a service oriented approach. The outcomes of this work are published in a case study on the Cumulus project led by Roehampton University in partnership with Canterbury Christ Church University, De Montfort University, the University of Lincoln, the University of Nottingham and Unit4.

Within the Course Data programme a number of different approaches are being taken and the following are some examples of institutions who are endeavouring to deliver a broader curriculum management solution in tandem with their XCRI-CAP feed:

- The Courtauld Institute of Art has consolidated data from a number of different sources into a Drupal content management system and has released a piece of open source software that permits the creation of an XCRI-CAP compatible feed from Drupal CMS. A number of other institutions are interested in using this open source product.

- The University of Exeter created the IPaMS (Integrated Programme and Module System) as part of an earlier Jisc programme and is continuing its rollout. The system is freely available for others to use under an open source license and full technical details can be found on the project blog. Features include:

- $\quad$ An XML specification for programme descriptors and module templates.

- $\quad$ An open database schema to hold programme templates and module descriptors including version control to support the approval process and an archive facility.

- A web application to allow access to the data for editing and downloading with automatic notification of change.

- Web services to allow transfer of templates and descriptors to and from the database.

- A fully populated database using data from one University academic unit interfacing with the SITS student records system and the Moodle VLE.

- A fully documented on-line toolkit available freely under open source licence.

- The University of Lincoln has completed and rolled out the implementation of its Academic Programme Management System (APMS) which provides a system for recording academic programme information; proposing, validating, modifying, revalidating or deleting programmes, and for producing Diploma Supplements. It provides automated version control and archiving of definitive programme information and is used for the production of information such as marketing material and (KIS) data. The University has published its Invitation to Tender material: ITT198-1; Requirements: ITT198-1 Annex 1 to Appendix A Requirements List; Pricing and Questions: ITT198-1 Appendix B.

- London Metropolitan University has developed an Integrated Course Data Management application and has made the requirements specification and data model for the application available on the project website. The technologies in use include: Oracle database, Railo, Coldbox Framework, Bootstrap HTML/CSS framework and ValidateThis Framework. 
A number of institutions are using an Enterprise Service Bus (ESB) approach to exchange data between a number of different systems and the solution offered by the Jisc Advance Nexus service is being considered by the University of Birmingham and Royal Holloway University of London with Cranfield University also potentially interested.

\section{TANGIBLE BENEFITS}

Although process change and the associated systems developments are still very much work in progress in many places, most of the universities have already taken some very significant steps and tangible benefits have been realised. These include

- a 'single source of truth': many institutions are creating centralised databases of information

- improved version control: this is very much ongoing work and many universities are seeking further opportunities to exchange thoughts and practice with other institutions.

- improved workflows: many projects have produced useful maps of their 'As Is' and 'To Be' processes that could be helpful to others undertaking similar reviews and the programme will be publishing some of these.

- automation of manual processes: although there is felt to be a need for further support around the change management aspects of moving from paper-based to digital processes.

- some centralisation of data input

- more user-friendly programme specifications: some universities are finding that programme information is being written in more student friendly language to aid its reuse for a wider range of purposes.

- development of information management policies

The other main benefit is of course the automated creation of the standardised course data feeds that now supply many of the institutions' own websites and are available for others to aggregate and use e.g. in the UK they will be used by the national careers service and a service providing information about postgraduate opportunities. There are many other potential uses of the data feeds and these have been explored in a number of demonstrator projects e.g. an open source Facebook application and an application to integrate targeted information about suitable progression opportunities into the Moodle VLE.

\section{REFERENCES}

Beetham H. (2009) Baselining the institutional processes of curriculum design. Report produced for Jisc. Available at http://www.jisc.ac.uk/curriculumdesign

Ferrell, G. (2012a) JISC Course Data Programme: early experiences of implementing standardised course advertising information. Report produced for Jisc. Available at: http://www.jisc.ac.uk/whatwedo/programmes/elearning/coursedata.aspx

Ferrell, G. (2012b) Feast or famine: progress in implementing standardised course data feeds. Report produced for Jisc. Available at: http://www.jisc.ac.uk/whatwedo/programmes/elearning/coursedata.aspx

Higher Education Statistics Agency (2011) What is a Course? Report produced for Jisc. Available at: http://www.hesa.ac.uk/dox/publications/The_Course_Report.pdf [Accessed 20 May 2012].

\section{AUTHORS' BIOGRAPHIES}

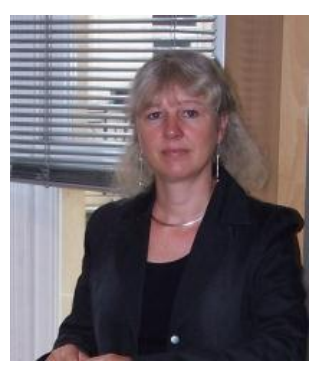

Gill has teaching and research experience and has held senior management positions in a number of university administrative functions as well as directing a UK support service enhancing the use of ICT in further and higher education. She acts as a consultant to universities and national agencies in both the UK and Europe and has been an invited speaker at many national and international events. Current interests include: data and information management, technology enhanced learning, assessment and feedback and learning space design.

http://uk.linkedin.com/in/gillferrell 


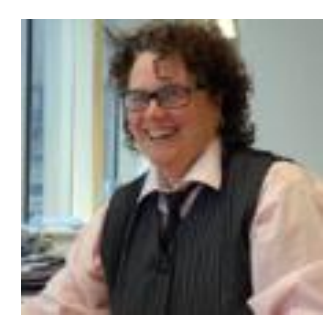

Janette is a Researcher/Analyst at Jisc infoNet, hosted by Northumbria University. Her experience of working in higher education began in 1990 and she has worked in a number of disciplinary and operational areas across university administration and professional services since then. In 2003 she joined the Jisc infoNet team where her work includes keeping a 'watching brief' on activity areas within the sector and beyond and supporting the production of online infoKits and other resources. Current interests include: learning space design, internationalisation, course information management and the professionalisation of University Administration.

http://www.linkedin.com/in/janettehillicks. 